\title{
REVIEW
}

\section{Mechanisms of multiple myeloma bone disease}

\author{
Deborah L Galson ${ }^{1}$, Rebecca Silbermann² and G David Roodman² \\ ${ }^{1}$ Department of Medicine, Division of Hematology/Oncology, University of Pittsburgh, Pittsburgh, PA, USA. \\ 2Department of Medicine, Division of Hematology/Oncology, Indiana University, Indianapolis, IN, USA.
}

\begin{abstract}
Multiple myeloma is the second most common hematological malignancy and the most frequent cancer to involve the skeleton. Multiple myeloma bone disease (MMBD) is characterized by abnormal bone remodeling with dysfunction of both bone resorption and bone formation, and thus can be used as a paradigm for other inflammatory bone diseases, and the regulation of osteoclasts and osteoblasts in malignancy. Studies of MMBD have identified novel regulators that increase osteoclastogenesis and osteoclast function, repress osteoblast differentiation, increase angiogenesis, or permanently alter stromal cells. This review will discuss the current understanding of mechanisms of osteoclast and osteoblast regulation in MMBD, and therapeutic approaches currently in use and under development that target mediators of bone destruction and blockade of bone formation for myeloma patients, including new anabolic therapies.
\end{abstract}

BoneKEy Reports 1, Article number: 135 (2012) | doi:10.1038/bonekey.2012.135

Multiple myeloma bone disease (MMBD) is an example of extremely abnormal bone remodeling with severe dysfunction of both bone resorption and bone formation. ${ }^{1,2}$ Thus, myeloma serves as a paradigm for other inflammatory bone diseases and the regulation of osteoclasts and osteoblasts in cancer. The accessibility of myeloma cells has allowed in-depth analysis of the mechanisms involved in cancer invasion of the bone. Importantly, studies of MMBD have identified novel regulators that increase osteoclastogenesis and osteoclast function, as well as others that repress bone marrow stromal cell (BMSC) differentiation into bone-building osteoblasts, or increase angiogenesis as is the characteristic of this malignancy.

Myeloma is the most frequent cancer to involve the skeleton, and over $80 \%$ of myeloma patients have bone disease..$^{3,4}$ MMBD has a tremendous impact on patient quality of life, and can result in severe bone pain, pathological fractures, hypercalcemia and increased mortality. ${ }^{5}$ Almost $20 \%$ of myeloma patients will present with a pathological fracture, and almost $60 \%$ of patients will sustain a pathological fracture over their disease course. ${ }^{6,7}$ Patients with pathological fractures have a $20 \%$ increase in mortality compared with patients without pathological fractures, and the cost of myeloma bone disease adds at least $\$ 50000$ to the care costs for each patient compared with myeloma patients without bone disease. ${ }^{8,9}$ Importantly, MMBD can continue to progress even when patients are in complete remission from their tumor. In this review, the mechanisms responsible for MMBD and the therapeutic approaches derived from knowledge of these mechanisms will be discussed.

\section{Mechanisms of MMBD}

MMBD is characterized by purely osteolytic bone destruction, with markedly increased osteoclast activity and little or no osteoblast activity, resulting in characteristic 'punched-out' lesions on skeletal X-rays. ${ }^{10}$ As there is little or no new bone formation in response to the bone destruction, bone scans can severely underestimate the extent of MMBD. ${ }^{11}$ In myeloma, the increased bone destruction is mediated by the osteoclast and not tumor cells themselves, although tumor cells can directly stimulate osteoclast formation. ${ }^{12}$ In addition, myeloma cells induce cells in the marrow microenvironment to produce factors that drive osteoclast formation and suppress osteoblast formation. Immune cells also contribute to these processes through production of cytokines and adhesion molecules that increase myeloma cell growth and enhance myeloma cell chemoresistance, increase osteoclastogenesis (in part, by driving dendritic cell and tumor-associated macrophages towards the osteoclast lineage), suppress osteoblastogenesis and polarize T-cell subsets from predominantly Th1 to Th17. ${ }^{13-16}$ The marrow stromal cells and osteoclasts produce factors that promote tumor growth, both directly by acting on the myeloma cells ${ }^{17}$ and indirectly by increasing angiogenesis. ${ }^{18-20}$ Finally, the bone resorption process releases immobilized growth factors, such as transforming growth factor- $\beta$ (TGF $\beta$ ), from the bone matrix, which also drive tumor growth. ${ }^{21}$ This 'vicious cycle' of bone destruction whereby myeloma cells drive bone destruction, which in turn increases tumor growth, highlights the critical role that bone disease has in myeloma. All active multiple myeloma patients progress from monoclonal gammopathy of unknown

Correspondence: Dr GD Roodman, Department of Medicine, Indiana University, 980 West Walnut, Suite C312, Indianapolis, IN 46202, USA.

E-mail: groodman@iupui.edu

Received 20 April 2012; accepted 11 June 2012; published online 1 August 2012 
significance, a premalignant plasma cell disorder without osteolytic lesions. ${ }^{22}$ As the cytogenetic changes present in plasma cells from active multiple myeloma patients are already present in almost all monoclonal gammopathy of unknown significance patients regardless of whether they progress to multiple myeloma or not, ${ }^{23,24}$ extrinsic changes, such as alterations in the bone marrow microenvironment that previously controlled tumor growth, may contribute to progression. The recent MRC Myeloma IX trial demonstrated that blocking osteoclast activity increases survival of myeloma patients. ${ }^{25}$ Similarly, enhancing marrow stromal cell differentiation into osteoblasts decreases tumor growth and bone destruction, as well as increases bone formation. 26,27 Unfortunately, myeloma is still incurable for most patients and MMBD remains a major contributor to the morbidity and mortality of myeloma patients.

\section{Factors Driving Osteoclast Formation and Activity in MMBD}

Early studies of MMBD demonstrated that myeloma cells produce bone-resorbing factors, which were termed 'osteoclast-activating factors (OAF)'. The OAFs were identified in conditioned media from myeloma cell lines and stimulated bone resorption in bone organ culture systems. ${ }^{12}$ Myeloma cells also stimulate cells in the marrow microenvironment, in particular, the marrow stromal cells and T cells, to increase the production of OAFs and decrease the production of osteoclast inhibitory factors. Multiple factors have since been identified as important OAFs in myeloma, including receptor activator of nuclear factor- $\kappa B$ (RANKL), macrophage inflammatory protein$1 \alpha$ (MIP-1 $\alpha$ ), tumor necrosis factor- $\alpha$ (TNF- $\alpha$ ), interleukin (IL)-3 and IL-6. Intriguingly, several of these OAFs also suppress osteoblast formation and/or support myeloma cells directly, indicating that they have multiple roles in MMBD. Besides releasing immobilized growth factors from the bone matrix, osteoclasts secrete several factors that support myeloma cells, including IL-6 (the most important growth factor for multiple myeloma cells), ${ }^{28}$ annexin II (AXII), ${ }^{29}$ osteopontin, ${ }^{30}$ fibroblast activation protein, ${ }^{31}$ BAFF (B-cell-activating factor belonging to the TNF family) and APRIL (a proliferation-inducing ligand). ${ }^{32}$ Figure 1a summarizes these interactions.

Receptor activator of nuclear factor-кB. The ratio of RANKL (TNFSF11 - TNF superfamily member 11), which interacts with its receptor RANK (TNFRSF11A) on osteoclast progenitors to induce osteoclastogenesis, and the soluble decoy receptor for RANKL, osteoprotegerin (OPG; TNFRSF11B) in bone is critical for the regulation of lytic activity in both normal and myelomatous bone. ${ }^{33}$ Myeloma cells both produce and induce production of RANKL by marrow stromal cells. Pearse et al. ${ }^{34}$ initially demonstrated that RANKL was increased and OPG was suppressed in the microenvironment of patients with myeloma. Several laboratories have reported that myeloma cells produce low levels of RANKL; however, it is unclear if these levels are sufficient to support osteoclast formation. ${ }^{35-38}$ Myeloma cells do induce production of high levels of RANKL by marrow stromal cells through adhesive interactions between $\alpha 4 \beta 1$ integrin on myeloma cells and vascular cell adhesion molecule-1 (VCAM-1) on marrow stromal cells, ${ }^{39}$ as well as by soluble factors produced by myeloma cells, such as TNF- $\alpha^{28,40}$ and Dickkopf1 (DKK1). ${ }^{41}$ Further enhancing the effects of increased RANKL in myeloma is the decreased production of OPG by marrow stromal cells via inhibition of osteoblast differentiation, decreased transcription of OPG and degradation of OPG by myeloma cell endocytosis of the OPG bound to CD138 (syndecan-1). ${ }^{42,43}$ Thus, the ratio of RANKL to OPG in myeloma patients is markedly increased and drives osteoclastogenesis. Additionally, the ratio of RANKL to OPG, detectable in the sera from myeloma patients, impacts prognosis. Patients with high RANKL:OPG ratios have inferior survival compared with patients with normal or intermediate levels of RANKL:OPG. ${ }^{44}$ The importance of increased RANKL expression in myeloma has been clearly shown in preclinical models. Blocking RANKL activity with OPG or a soluble RANK receptor (RANK-Fc) reduced tumor burden and bone destruction in these animal models. ${ }^{35,45}$ The impact of denosumab, a human monoclonal antibody to RANKL, on bone metastases in patients with breast and prostate cancer, treatment-induced bone disease due to prostate cancer, and osteoporosis has been evaluated. ${ }^{46}$ Denosumab treatment resulted in a statistically significant improvement in bone mineral density in patients with non-metastatic prostate or breast cancer. ${ }^{47,48}$ In addition, the prostate cancer patients receiving denosumab had a reduced incidence of new vertebral fractures at 36 months. ${ }^{48}$ A recent clinical trial, which examined the efficacy of denosumab in approximately 1500 patients with solid tumor bone metastasis and 200 patients with myeloma showed that denosumab reduced skeleton-related events and time to the next skeleton-related events as effectively as zoledronic acid.

Tumor necrosis factor- $\alpha$. TNF- $\alpha$ is elevated in myeloma patients. ${ }^{49}$ Several studies have shown that TNF- $\alpha$ and IL$1 \beta$ mRNA is produced by some myeloma cells, but it has been difficult to clearly demonstrate that myeloma cells produce significant quantities of these cytokines themselves. ${ }^{50}$ Myeloma cells do induce high levels of TNF- $\alpha$ in the marrow microenvironment. ${ }^{17}$ TNF- $\alpha$ has multiple functions in myeloma bone disease. TNF- $\alpha$ increases marrow stromal cell production of RANKL, IL-6 and other osteoclastogenic cytokines. Xu et al. ${ }^{51}$ recently reported that myeloma cells and TNF- $\alpha$ both increase the transcription factor XBP1s (X-box binding protein 1 spliced) in marrow stromal cells, and that this contributes to the increased production of VCAM-1, RANKL and IL-6, as well as enhanced stromal cell support of myeloma cell growth and osteoclast formation.

TNF- $\alpha$ is also a potent inducer of osteoclast formation itself, and can either directly increase osteoclast formation or enhance the effects of RANKL. ${ }^{52,53}$ In addition, TNF- $\alpha$ can block osteoblast differentiation from marrow stromal cells by decreasing the expression of critical osteoblast transcription factors, such as runt-related transcription factor 2 (Runx2), TAZ (transcriptional co-activator with PDZ-binding motif) and osterix, induce apoptosis of mature osteoblasts, and increase support of myeloma cells by induction of IL-6. ${ }^{15,54}$

Macrophage inflammatory-1 $\alpha$. MIP-1 $\alpha$ (chemokine C-C motif ligand 3 ) is a potent osteoclast-inducing chemokine produced by myeloma cells that, like TNF- $\alpha$, can both directly stimulate human osteoclast formation and potentiate the effects of RANKL. ${ }^{15}$ Further, MIP-1 $\alpha$ also enhances myeloma adhesion to marrow stromal cells, thereby enhancing marrow stromal cells production of the OAFs RANKL, TNF- $\alpha$ and IL-6, as well as the 
angiogenic factor vascular endothelial growth factor (VEGF). Elevated MIP-1 $\alpha$ gene expression and secretion by myeloma cells is very highly correlated with bone destruction in myeloma patients and decreased survival. ${ }^{55-57}$ Blocking MIP- $1 \alpha$ activity, either with antisense to MIP- $1 \alpha$ or by treating a mouse model of myeloma with an antibody to MIP- $1 \alpha$, resulted in decreased tumor burden and bone destruction. ${ }^{58,59} \mathrm{MIP}-1 \alpha$ binds to three different receptors: CCR1, CCR5 and CCR9. CCR1 is the major receptor driving osteoclast formation in response to MIP-1 $\alpha$, as well as myeloma cell chemotaxis, growth and survival induced by MIP-1 $\alpha .{ }^{60,61}$ In addition, small molecule antagonists to CCR1 have been studied in models of myeloma and have been shown to block both tumor growth and bone destruction. ${ }^{62,63}$ CCR1 antagonists are being developed by several pharmaceutical companies ${ }^{64}$ and should be in clinical trial for myeloma in the future.

Interleukin-3/activin A. IL-3 is produced by myeloma cells and T cells in the myeloma microenvironment, and can both stimulate osteoclastogenesis ${ }^{65}$ and inhibit osteoblast formation. ${ }^{6} \mathrm{IL}-3$ levels are increased in the marrow of
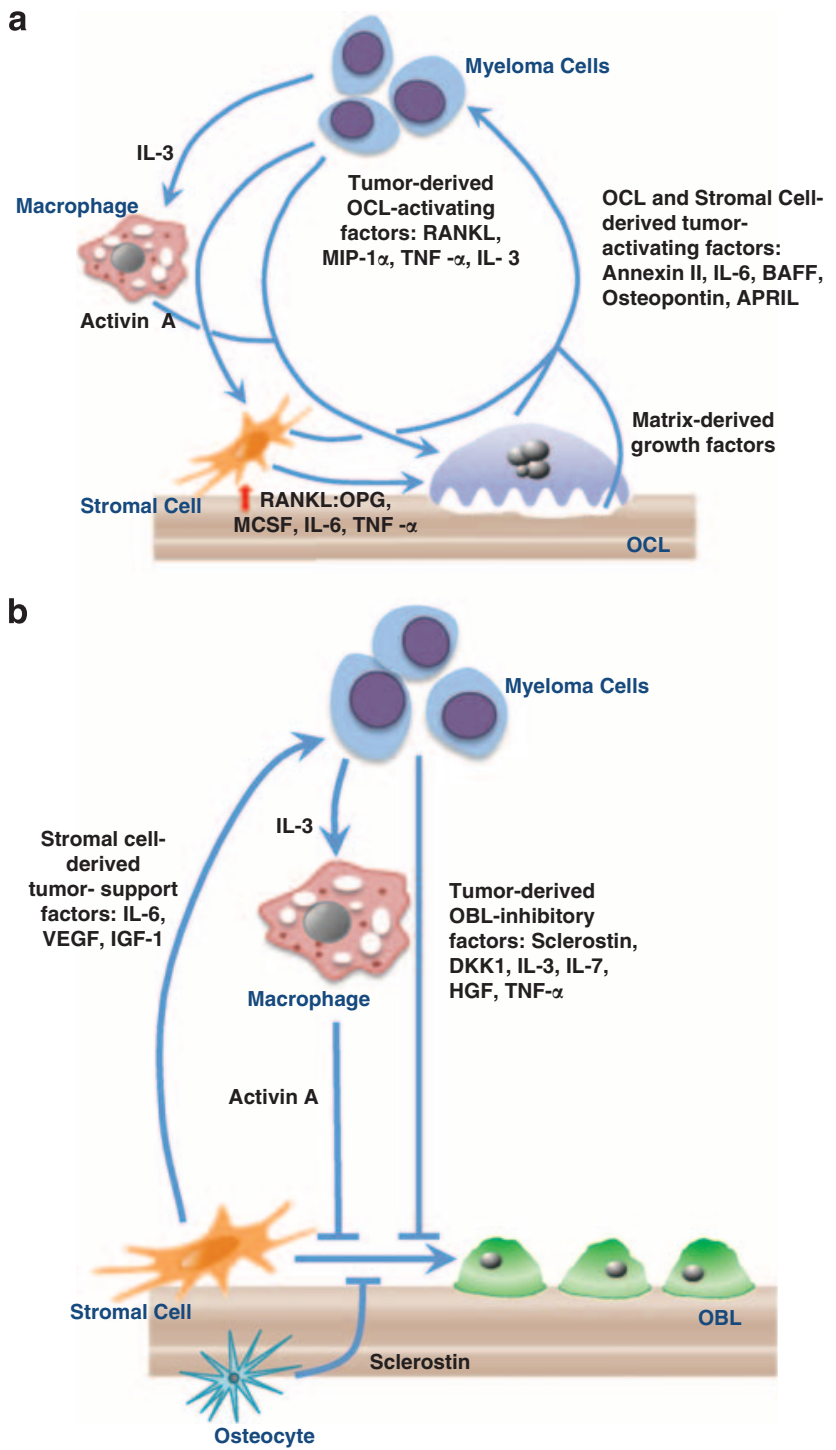

approximately $70 \%$ of the myeloma patients with a median level of $100 \mathrm{pg} \mathrm{ml}^{-1}$. 65 Although IL-3 is a potent inducer of osteoclast formation, this effect appears to be indirect. Silbermann et al. ${ }^{67}$ recently reported that IL-3 stimulates marrow macrophages in the myeloma microenvironment to produce activin A, a TGF $\beta$ family member, ${ }^{67}$ and that anti-activin $A$ inhibits the effects of IL-3 on osteoclast formation. Activin A is known to directly induce osteoclast formation and enhance the effects of RANKL on osteoclast formation. ${ }^{68}$ Vallet et al. ${ }^{27}$ reported that levels of activin $A$ are increased in marrow plasma and peripheral blood from patients with myeloma, and that marrow stromal cells and osteoclasts are the major source of activin A in myeloma patients. Most recently, Terpos et al. ${ }^{69}$ reported that circulating activin A levels are elevated in newly diagnosed symptomatic myeloma patients as compared with controls, and that patients with relapsed disease had elevated activin A levels compared with symptomatic patients at the time of diagnosis. Additionally, elevated activin A levels correlated with advanced disease stage and were associated with increased bone resorption and extensive bone disease. Interestingly, Erlich et al. ${ }^{66}$ found that the mechanism of IL-3 suppression of osteoblast differentiation required the participation of CD45 + cells. The osteoclast precursor is CD45,$+{ }^{66}$ suggesting that activin $A$ is involved as a cross-talk regulatory molecule between osteoclast and osteoblast precursors in both directions.

Activin A signals through the activin A type-IIA receptor to increase bone resorption and suppress osteoblast differentiation by inhibiting production of the critical transcription factor DIx5. An activin $A$ receptor antagonist (soluble activin receptor

Figure 1 Mechanisms of myeloma bone disease: increased osteoclast (OCL) activity and suppressed osteoblast (OBL) formation in myeloma result in tumor growth and bone destruction. In myeloma bone disease, osteoclastogenesis is favored and osteoblastogenesis is inhibited. (a) Increased OCL activity in myeloma. Multiple factors produced by myeloma cells increase OCL activity. Myeloma cells produce OCL-activating factors (OAFs) that directly increase OCL activity and stimulate marrow stromal cells and $T$ cells to increase production of OAFs and decrease production of OCL inhibitory factors. OAFs produced by myeloma cells include RANKL, MIP- $1 \alpha$, IL- 3 and TNF- $\alpha$. In addition, IL-3 activates tumor-associated macrophages to produce activin A, further increasing OCL activity. Myeloma cells also induce marrow stromal cells production of OAFS, such as RANKL, macrophage colony-stimulating factor (MCSF), IL-6 and TNF- $\alpha$, and decrease expression of OPG, which enhances OCL formation. Amplifying this process, OCLs and stromal cells secrete soluble factors, such as IL-6, annexin II, osteopontin, BAFF and APRIL, which further stimulate tumor growth. Finally, the enhanced bone destructive process releases growth factors (TGF $\beta$, insulin-like growth factors (IGFs), fibroblast growth factors (FGFs), platelet-derived growth factors (PDGFs), bone morphogenetic proteins (BMPs)) from the bone matrix that increase the growth of myeloma cells, exacerbating the osteolytic process. This results in a 'vicious cycle' of bone destruction. (b) OBL suppression in myeloma. Suppression of OBL differentiation by tumor-derived OBL-inhibitory factors, such as sclerostin, DKK1, IL-3, IL-7, HGF and TNF- $\alpha$, also has an important role in tumor growth, as mature OBL inhibit myeloma cell growth. In addition, IL-3, secreted by myeloma cells, stimulates release of activin A from macrophages in the bone marrow microenvironment to inhibit osteoblast formation. Myeloma cells also induce cells in the bone microenvironment to increase production of OBL suppressors. Osteocyte production of sclerostin and marrow stromal cell production of TNF- $\alpha$ are examples. TGF $\beta$ released from the bone matrix by the enhanced OCL activity in MMBD also inhibits OBL differentiation. Myeloma cells induce changes in marrow stromal cells that increase production of factors that support myeloma cells, such as IL-6, VEGF and IGF-1, in part via adhesive interactions through VCAM-1 on marrow stromal cells and $\alpha_{4} \beta_{1}$ on myeloma cells. Finally, bidirectional signaling between ephrin $\mathrm{B} 2$ in OCLs and its receptor, EphB4 in BMSC and OBL (not illustrated) negatively control osteoclast formation and promote osteoblast differentiation. Both ephrin B2 and EphB4 are decreased in myeloma, and enhancing ephrinB2-EphB4 signaling to decrease osteoclast function is a possible therapeutic target for MMBD. 
type-IIA fusion protein (ActRIIA.muFc; also called RAP-011)) has been shown by two groups to block bone destruction, stimulate bone formation and decrease tumor growth in a mouse model of myeloma. ${ }^{27,70}$ There is an ongoing clinical trial evaluating a humanized activin-A-soluble receptor antagonist (ACE-011) in myeloma patients, but the results are yet to be fully reported. However, ACE-011 effectively inhibited bone resorption markers and stimulated bone formation parameters in post-menopausal women in a double-blind placebo-controlled study. ${ }^{71}$

Interleukin-6. IL-6 is another potent inducer of human osteoclast formation ${ }^{72}$ produced in the myeloma microenvironment in response to myeloma cells and by myeloma cells themselves. ${ }^{73}$ IL-6 can directly induce human osteoclast formation and induce RANKL production. IL- 6 is also an anti-apoptotic factor and a growth factor for myeloma cells. Antibodies to IL-6 have been in clinical trials for patients with myeloma, and although a pilot study indicated that blocking IL-6 may decrease the growth of myeloma cells in patients, ${ }^{74}$ to-date, none of these trials have been exceptionally successful. These results suggest that targeting IL- 6 by itself is not sufficient to inhibit bone destruction and myeloma tumor growth.

Annexin II. AXII is a recently identified factor produced by stromal cells and osteoclasts that is important in osteoclast formation, hematopoietic stem cell mobilization and homing of prostate cancer cells to the bone. ${ }^{75} \mathrm{AXII}$ has been previously found to be upregulated in myeloma, and myeloma-derived AXII increases proliferation of myeloma cell lines, possibly through an autocrine mechanism. ${ }^{76,77}$ D'Souza et al. ${ }^{29}$ recently reported that AXII secreted by osteoclast and stromal cells enhances the growth of multiple myeloma cells in the bone marrow by binding to the AXII receptor on myeloma cells, primarily through a paracrine mechanism. Additionally, AXII can induce stromal cell production of RANKL, further stimulating osteoclast formation.

Ephrin B2/EphB4 Bidirectional Signaling. Bidirectional signaling between the ligand ephrin B2 in osteoclasts and its receptor EphB4 in the BMSC and osteoblasts has been reported to negatively control osteoclast formation from precursors (reverse signaling) and to promote osteoblast differentiation (forward signaling). ${ }^{78}$ Pennisi et al. ${ }^{79}$ found that ephrinB2 and EphB4 were decreased in BMSC in myeloma patients. EphB4-Fc activated ephrinB2 in osteoclasts, but not in the BMSC, and ephrinB2-Fc activated EphB4 in BMSC. Administration of either peptide to multiple myeloma-bearing SCID-hu mice stimulated osteoblastogenesis, bone formation and angiogenesis, but only EphB4-Fc also inhibited osteoclastogenesis and myeloma growth. Therefore, enhancing ephrinB2-EphB4 signaling is a possible therapeutic target for MMBD.

\section{Osteoblast Suppression in MMBD}

In addition to the markedly increased osteoclast activity in MMBD, osteoblast differentiation is severally inhibited in patients with myeloma and remains suppressed even after the tumor cells are eradicated. In the overwhelming majority of patients, myeloma bone lesions rarely heal, even when patients are in long-term complete remission without detectable myeloma cells in these lesions. A number of inhibitors of osteoblast differentiation have been identified in myeloma and are produced by myeloma cells or cells in the microenvironment. Along with TNF- $\alpha$, MIP- $1 \alpha$ and IL-3/activin A, which were discussed above, DKK1, sclerostin, TGF $\beta$, hepatocyte growth factor (HGF) and IL-7 inhibit osteoblast differentiation (Figure 1b). In addition, myeloma patients marrow stromal cells retain their aberrant properties, such as increased production of activin A, RANKL, IL-6 and XBP1s, as well as elevated Gfi1 and suppressed osteoblast differentiation, even after weeks in culture. This suggests that myeloma cells induce permanent changes in marrow stromal cells. Although myeloma cell products that can suppress osteoblast differentiation have been identified, the mechanisms responsible for the suppressed osteoblast activity in myeloma are just beginning to be understood. Further, the basis for the persistent block in osteoblast differentiation is unknown. The formation and differentiation of osteoblasts from marrow stromal cells requires the activity and function of the transcription factor Runx2/Cbfal (Runx2). Runx2-deficient mice (Run $x 2^{-/-}$), which are embryonic lethal, completely lack osteoblasts and bone formation, 80 demonstrating the critical role of Runx2 in osteoblast activity. Inhibition of Runx2 activity in osteoblast precursors has been clearly demonstrated in MMBD, ${ }^{81}$ but the mechanisms underlying the inhibition of Runx2 activity are unclear. The myeloma cells also induce the marrow stromal cells to produce factors that support the myeloma cell growth survival, and chemoresistance, such as IL-6, AXII, VCAM-1, VEGF and IGF-1. Thus, even in remission, the bone microenvironment is locked into a myeloma-supportive phenotype that is primed to protect and promote the growth of any myeloma cells that escaped eradication. Yaccoby and coworkers reported that mature osteoblasts suppress myeloma cell growth via production of Decorin. ${ }^{82,83}$ These results suggest that suppression of osteoblast differentiation in myeloma enhances tumor growth because of the toxic effects of mature osteoblasts on myeloma cells.

Dickkopf1. Wnt signaling, leading to activation and nuclear translocation of $\beta$-catenin, is an important regulator of osteoblast formation. ${ }^{84} \mathrm{DKK} 1$, a Wnt signaling antagonist, is a major inhibitor of osteoblast differentiation in myeloma. ${ }^{85}$ Myeloma cells produce high levels of DKK1, and DKK1 gene expression correlates with the extent of bone disease in myeloma. Although there is strong data that DKK1 can inhibit osteoblast formation, there is a controversy over whether DKK1 levels correlate with myeloma disease severity, as DKK1 expression is lost as multiple myeloma bone disease progresses, ${ }^{85}$ and if myeloma cells produce enough DKK1 to inhibit normal human osteoblast formation. ${ }^{86}$ DKK1 can enhance RANKL production as well as suppress OPG expression, further driving the bone-destructive process. ${ }^{41}$ Preclinical studies with blocking antibodies to DKK1 (BHQ880) have clearly shown that they can enhance bone formation and block tumor growth in murine models of myeloma bone disease. ${ }^{87}$ Anti-DKK1 does not have direct anti-tumor effects, although anti-DKK1 may suppress tumor growth via its effects on osteoblast differentiation. Antibodies to DKK1 are now in clinical trials for smoldering and active myeloma. Several other Wnt signaling antagonists have been identified in myeloma, including soluble frizzle-related protein II and III.

Sclerostin. Several recent studies have shown that myeloma cells may produce sclerostin or induce sclerostin expression in 
myeloma patients. ${ }^{88,89}$ Sclerostin is an inhibitor of the downstream Wnt signaling pathway and is produced by osteocytes to inhibit osteoblast differentiation. Antibodies to sclerostin are potent inducers of bone formation in preclinical models. ${ }^{90}$ Sclerostin levels correlate with the extent of bone destruction in patient with myeloma. ${ }^{89}$ Giuliani and coworkers recently reported that osteocyte apoptosis occurs in myeloma, and apoptotic osteocytes may release both RANKL and sclerostin. ${ }^{91}$

Transforming growth factor- $\boldsymbol{\beta}$. Active TGF $\beta$, deposited into bone matrix in a latent form by osteocytes and osteoblasts, is released by the enhanced osteoclast activity in MMBD. A major action of TGF $\beta$ in MMBD is to inhibit osteoblast differentiation. ${ }^{92}$ Takeuchi et al. ${ }^{92}$ reported that blockade of TGF $\beta$ signaling through the TGF $\beta$ type-I receptor by an inhibitor of the receptor's kinase function, Ki26894, restored osteoblast differentiation suppressed by either TGF $\beta$, myeloma cell line conditioned media, or bone marrow plasma from myeloma patients. ${ }^{92}$ Oral administration of Ki26894 to a SCID-rab model of MMBD injected with INA-6 myeloma cells revealed that targeting TGF $\beta$ signaling in vivo decreased myeloma cell growth in the bone, protected the bone from destruction and preserved osteoblast differentiation.

Hepatocyte growth factor. HGF is a negative modulator of BMP-induced osteoblast differentiation. ${ }^{54} \mathrm{~A}$ myeloma cell line (JJN-3) that produces large amounts of HGF, causes 99\% loss of osteoblast perimeter when injected into irradiated SCID mice. Standal et al. ${ }^{93}$ have shown that HGF could inhibit human osteoblast formation, and that myeloma patients with higher HGF levels in their sera had lower bone-specific alkaline phosphatase activity (a marker of osteoblast function).

Interleukin-7. IL-7 has also been identified as a suppressor of osteoblast differentiation. Giuliani et al. ${ }^{81}$ reported that IL-7 levels were increased in marrow plasma of patients with myeloma and did not suppress Runx2 transcriptional activity, but affected the differentiation of early and late osteoblast precursors by targeting Runx2 activity. IL-7 can also induce Gfi1 and enhance the effects of suboptimal TNF- $\alpha$ on osteoblast suppression, resulting in marked suppression of osteoblast differentiation. ${ }^{94}$

Gfi1. None of the soluble inhibitors of osteoblast differentiation produced or induced by myeloma cells explains the long-term suppression of osteoblast differentiation present in myeloma, even in patients in long-term remission. Recently, D'Souza et al. ${ }^{94}$ reported that myeloma cells induce expression of Gfi1, a transcriptional repressor of the Runx2 gene, in marrow stromal cells. They showed that marrow stromal cells isolated from myeloma patients had elevated levels of Gfi1, and that Gfi1 was a potent suppressor of osteoblast differentiation. Further, knockdown of Gfi1 in marrow stromal cells from patients with myeloma allowed them to differentiate toward the osteoblast lineage. Finally, marrow stromal cells from Gfi1 knock-out mice were partially resistant to the inhibitory effects of myeloma cells on osteoblast differentiation. In preliminary studies, Galson and colleagues $^{95}$ have shown that Gfi1 binds directly to the Runx2 promoter, that there are multiple Gfi1 sites within the Runx2 promoter, that mutation of the key Gfi1 binding site significantly prevents TNF- $\alpha$ repression of Runx2, and that Gfi1 can recruit histone-modifying enzymes to the Runx2 promoter, which may explain long-term suppression of osteoblast differentiation in patients with myeloma.

Adiponectin. Adiponectin has been identified by Fowler et al. ${ }^{96}$ as an adipocyte-derived factor that can protect osteoblast differentiation in myeloma, and increases myeloma cell apoptosis. They analyzed differentially expressed genes in bone marrow from KaLwRij that supported 5T myeloma growth as compared with bone marrow from the closely related C57BI6 mice that did not support 5T myeloma growth. They found that adiponectin expression was decreased in both mice and human bone marrows permissive for myeloma growth. Further, increasing adiponectin expression with the apolipoprotein peptide mimetic $\mathrm{L}-4 \mathrm{~F}$ not only reduced tumor burden and MMBD, but in the absence of myeloma cells induced a significant increase in both osteoblasts and bone formation rates without affecting osteoclasts. Thus, inducing adiponectin expression is another potential therapeutic target to treat the osteoblast suppression induced in MMBD.

\section{Summary}

Multiple factors that simulate osteoclast formation and suppress osteoblast differentiation are involved in the development of the lytic bone destruction characteristic of myeloma. The multiplicity of factors driving osteoclast activity and preventing new bone formation explains the severity of myeloma bone disease. As myeloma patients are living longer and continuing to suffer the sequelae of their bone disease, it is important to develop novel therapies that target the mediators of bone destruction and blockade of bone formation in these patients. Trials of new anabolic therapies to repair myeloma bone disease are ongoing, and new agents are needed if patients are to have an improved quality of life and prolonged survival.

\section{Conflict of Interest}

DLG and RS have no conflicts of interest. GDR is a member of the Amgen Advisory Board and is also the local PI for the Denosumab Trial in Myeloma.

\section{References}

1. Diamond T, Levy S, Day P, Barbagallo S, Manoharan A, Kwan YK. Biochemical, histomorphometric and densitometric changes in patients with multiple myeloma: effects of glucocorticoid therapy and disease activity. Br J Haematol 1997;97:641-648.

2. Giuliani N, Rizzoli V, Roodman GD. Multiple myeloma bone disease: pathophysiology of osteoblast inhibition. Blood 2006;108:3992-3996.

3. Mariotto A, Gigli A, Capocaccia R, Tavilla A, Clegg L, Depry M et al. Complete and limited duration cancer prevalence estimates. SEER Cancer Statistics Review, Bethesda, MD, 2002, pp 19.

4. Roodman GD. Pathogenesis of myeloma bone disease. Blood Cells Mol Dis 2004;32:290-292.

5. Terpos E, Berenson J, Cook RJ, Lipton A, Coleman RE. Prognostic variables for survival and skeletal complications in patients with multiple myeloma osteolytic bone disease. Leukemia 2010;24:1043-1049

6. Berenson JR, Lichtenstein A, Porter L, Dimopoulos MA, Bordoni R, George S et al. Efficacy of pamidronate in reducing skeletal events in patients with advanced multiple myeloma. Myeloma Aredia Study Group. N Engl J Med 1996;334:488-493.

7. Melton 3rd LJ, Kyle RA, Achenbach SJ, Oberg AL, Rajkumar SV. Fracture risk with multiple myeloma: a population-based study. J Bone Miner Res 2005;20:487-493.

8. Saad F, Lipton A, Cook R, Chen YM, Smith M, Coleman R. Pathologic fractures correlate with reduced survival in patients with malignant bone disease. Cancer2007;110:1860-1867.

9. Schulman KL, Kohles J. Economic burden of metastatic bone disease in the United States. Cancer 2007;109:2334-2342.

10. Dimopoulos MA, Moulopoulos LA, Datseris I, Weber D, Delasalle K, Gika D et al. Imaging of myeloma bone disease-implications for staging, prognosis and follow-up. Acta Oncol 2000; 39:823-827. 
11. Nilsson-Ehle $\mathrm{H}$, Holmdahl $\mathrm{C}$, Suurkula $\mathrm{M}$, Westin J. Bone scintigraphy in the diagnosis of skeletal involvement and metastatic calcification in multiple myeloma. Acta Med Scand 1982;211: 427-432.

12. Garrett IR, Durie BG, Nedwin GE, Gillespie A, Bringman T, Sabatini M et al. Production of lymphotoxin, a bone-resorbing cytokine, by cultured human myeloma cells. $N$ Engl J Med 1987;317:526-532.

13. Kukreja A, Radfar S, Sun BH, Insogna K, Dhodapkar MV. Dominant role of CD47thrombospondin-1 interactions in myeloma-induced fusion of human dendritic cells: implications for bone disease. Blood 2009;114:3413-3421.

14. Prabhala RH, Pelluru D, Fulciniti M, Prabhala HK, Nanjappa P, Song W et al. Elevated IL-17 produced by $\mathrm{TH} 17$ cells promotes myeloma cell growth and inhibits immune function in multiple myeloma. Blood 2010;115:5385-5392.

15. Roodman GD. Pathogenesis of myeloma bone disease. J Cell Biochem 2010;109:283-291.

16. Zheng Y, Cai Z, Wang S, Zhang X, Qian J, Hong S et al. Macrophages are an abundant component of myeloma microenvironment and protect myeloma cells from chemotherapy drug-induced apoptosis. Blood 2009;114:3625-3628.

17. Mitsiades CS, McMillin DW, Klippel S, Hideshima T, Chauhan D, Richardson PG et al. The role of the bone marrow microenvironment in the pathophysiology of myeloma and its significance in the development of more effective therapies. Hematol Oncol Clin North Am 2007;21: 1007-1034, vii-viii.

18. Bruni-Cardoso A, Johnson LC, Vessella RL, Peterson TE, Lynch CC. Osteoclast-derived matrix metalloproteinase-9 directly affects angiogenesis in the prostate tumor-bone microenvironment. Mol Cancer Res 2010;8:459-470.

19. Cackowski FC, Anderson JL, Patrene KD, Choksi RJ, Shapiro SD, Windle JJ et al. Osteoclasts are important for bone angiogenesis. Blood 2010;115:140-149.

20. Wang Y, Wan C, Deng L, Liu X, Cao X, Gilbert SR et al. The hypoxia-inducible factor alpha pathway couples angiogenesis to osteogenesis during skeletal development. J Clin Invest 2007;117:1616-1626.

21. Dallas SL, Rosser JL, Mundy GR, Bonewald LF. Proteolysis of latent transforming growth factorbeta (TGF-beta)-binding protein-1 by osteoclasts. A cellular mechanism for release of TGF-beta from bone matrix. J Biol Chem 2002;277:21352-21360.

22. Landgren O, Kyle RA, Pfeiffer RM, Katzmann JA, Caporaso NE, Hayes RB et al. Monoclonal gammopathy of undetermined significance (MGUS) consistently precedes multiple myeloma: a prospective study. Blood 2009;113:5412-5417.

23. Landgren O, Waxman AJ. Multiple myeloma precursor disease. JAMA 2010;304:2397-2404.

24. Munshi NC, Avet-Loiseau H. Genomics in multiple myeloma. Clin Cancer Res 2011;17: 1234-1242.

25. Morgan GJ, Davies FE, Gregory WM, Cocks K, Bell SE, Szubert AJ et al. First-line treatment with zoledronic acid as compared with clodronic acid in multiple myeloma (MRC Myeloma IX): a randomised controlled trial. Lancet 2010;376:1989-1999.

26. Heath DJ, Chantry AD, Buckle CH, Coulton L, Shaughnessy Jr JD, Evans HR et al. Inhibiting Dickkopf-1 (Dkk1) removes suppression of bone formation and prevents the development of osteolytic bone disease in multiple myeloma. J Bone Miner Res 2009;24:425-436.

27. Vallet S, Mukherjee S, Vaghela N, Hideshima T, Fulciniti M, Pozzi S et al. Activin A promotes multiple myeloma-induced osteolysis and is a promising target for myeloma bone disease. Proc Natl Acad Sci USA 2010;107:5124-5129.

28. Hideshima T, Chauhan D, Podar K, Schlossman RL, Richardson P, Anderson KC. Novel therapies targeting the myeloma cell and its bone marrow microenvironment. Semin Oncol 2001;28: $607-612$.

29. D'Souza S, Kurihara N, Shiozawa Y, Joseph J, Taichman R, Galson DL et al. Annexin II interactions with the annexin II receptor enhance multiple myeloma cell adhesion and growth in the bone marrow microenvironment. Blood 2012;119:1888-1896.

30. Abe M, Hiura K, Wilde J, Shioyasono A, Moriyama K, Hashimoto T et al. Osteoclasts enhance myeloma cell growth and survival via cell-cell contact: a vicious cycle between bone destruction and myeloma expansion. Blood 2004;104:2484-2491.

31. Ge Y, Zhan F, Barlogie B, Epstein J, Shaughnessy Jr J, Yaccoby S. Fibroblast activation protein (FAP) is upregulated in myelomatous bone and supports myeloma cell survival. Br J Haematol 2006:133:83-92.

32. Abe M, Kido S, Hiasa M, Nakano A, Oda A, Amou H et al. BAFF and APRIL as osteoclastderived survival factors for myeloma cells: a rationale for $\mathrm{TACl}-\mathrm{Fc}$ treatment in patients with multiple myeloma. Leukemia 2006;20:1313-1315.

33. Kobayashi Y, Udagawa N, Takahashi N. Action of RANKL and OPG for osteoclastogenesis. Crit Rev Eukaryot Gene Expr 2009;19:61-72.

34. Pearse RN, Sordillo EM, Yaccoby S, Wong BR, Liau DF, Colman N et al. Multiple myeloma disrupts the TRANCE/osteoprotegerin cytokine axis to trigger bone destruction and promote tumor progression. Proc Natl Acad Sci USA 2001;98:11581-11586.

35. Croucher PI, Shipman CM, Lippitt J, Perry M, Asosingh K, Hijzen A et al. Osteoprotegerin inhibits the development of osteolytic bone disease in multiple myeloma. Blood 2001;98:3534-3540.

36. Lai FP, Cole-Sinclair M, Cheng WJ, Quinn JM, Gillespie MT, Sentry JW et al. Myeloma cells can directly contribute to the pool of RANKL in bone bypassing the classic stromal and osteoblast pathway of osteoclast stimulation. Br J Haematol 2004;126:192-201.

37. Sezer O, Heider U, Jakob C, Eucker J, Possinger K. Human bone marrow myeloma cells express RANKL. J Clin Oncol 2002;20:353-354.

38. Sezer O, Heider U, Jakob C, Zavrski I, Eucker J, Possinger K et al. Immunocytochemistry reveals RANKL expression of myeloma cells. Blood 2002;99:4646-4647; author reply 4647.

39. MoriY, Shimizu N, Dallas M, Niewolna M, Story B, Williams PJ et al. Anti-alpha4 integrin antibody suppresses the development of multiple myeloma and associated osteoclastic osteolysis. Blood 2004;104:2149-2154.
40. Hiruma Y, Honjo T, Jelinek DF, Windle JJ, Shin J, Roodman GD et al. Increased signaling through p62 in the marrow microenvironment increases myeloma cell growth and osteoclast formation. Blood 2009;113:4894-4902.

41. Qiang YW, Chen Y, Stephens O, Brown N, Chen B, Epstein J et al. Myeloma-derived Dickkopf-1 disrupts Wnt-regulated osteoprotegerin and RANKL production by osteoblasts: a potential mechanism underlying osteolytic bone lesions in multiple myeloma. Blood 2008;112: 196-207.

42. Roodman GD, Dougall WC. RANK ligand as a therapeutic target for bone metastases and multiple myeloma. Cancer Treat Rev2008;34:92-101.

43. Seidel C, Hjertner O, Abildgaard N, Heickendorff L, Hjorth M, Westin J et al. Serum osteoprotegerin levels are reduced in patients with multiple myeloma with lytic bone disease. Blood 2001;98:2269-2271.

44. Terpos E, Szydlo R, Apperley JF, Hatjiharissi E, Politou M, Meletis J et al. Soluble receptor activator of nuclear factor kappaB ligand-osteoprotegerin ratio predicts survival in multiple myeloma: proposal for a novel prognostic index. Blood 2003;102:1064-1069.

45. Yaccoby S, Pearse RN, Johnson CL, Barlogie B, Choi Y, Epstein J. Myeloma interacts with the bone marrow microenvironment to induce osteoclastogenesis and is dependent on osteoclast activity. Br J Haematol 2002;116:278-290.

46. Dougall WC. Molecular pathways: osteoclast-dependent and osteoclast-independent roles of the RANKL/RANK/OPG pathway in tumorigenesis and metastasis. Clin Cancer Res 2012;18: 326-335.

47. Ellis GK, Bone HG, Chlebowski R, Paul D, Spadafora S, Smith J et al. Randomized trial of denosumab in patients receiving adjuvant aromatase inhibitors for nonmetastatic breast cancer. J Clin Oncol 2008:26:4875-4882.

48. Smith MR, Egerdie B, Hernandez Toriz N, Feldman R, Tammela TL, Saad F et al. Denosumab in men receiving androgen-deprivation therapy for prostate cancer. N Engl J Med 2009;361: 745-755.

49. Li B, Shi M, Li J, Zhang H, Chen B, Chen L et al. Elevated tumor necrosis factor-alpha suppresses TAZ expression and impairs osteogenic potential of Flk-1+ mesenchymal stem cells in patients with multiple myeloma. Stem Cells Dev2007;16:921-930.

50. Yamamoto I, Kawano M, Sone T, Iwato K, Tanaka H, Ishikawa H et al. Production of interleukin 1 beta, a potent bone resorbing cytokine, by cultured human myeloma cells. Cancer Res 1989; 49:4242-4246.

51. Xu G, Liu K, Anderson J, Patrene K, Lentzsch S, Roodman GD et al. Expression of XBP1s in bone marrow stromal cells is critical for myeloma cell growth and osteoclast formation. Blood 2012;119:4205-4214.

52. Kim N, Kadono Y, Takami M, Lee J, Lee SH, Okada F et al. Osteoclast differentiation independent of the TRANCE-RANK-TRAF6 axis. J Exp Med 2005;202:589-595.

53. Lam J, Takeshita S, Barker JE, Kanagawa O, Ross FP, Teitelbaum SL. TNF-alpha induces osteoclastogenesis by direct stimulation of macrophages exposed to permissive levels of RANK ligand. J Clin Invest 2000;106:1481-1488.

54. Roodman GD. Osteoblast function in myeloma. Bone 2011:48:135-140.

55. Hashimoto T, Abe M, Oshima T, Shibata H, Ozaki S, Inoue D et al. Ability of myeloma cells to secrete macrophage inflammatory protein (MIP)-1alpha and MIP-1beta correlates with lytic bone lesions in patients with multiple myeloma. Br J Haematol 2004;125:38-41.

56. Magrangeas F, Nasser V, Avet-Loiseau H, Loriod B, Decaux O, Granjeaud S et al. Gene expression profiling of multiple myeloma reveals molecular portraits in relation to the pathogenesis of the disease. Blood 2003;101:4998-5006.

57. Terpos E, Politou M, Szydlo R, Goldman JM, Apperley JF, Rahemtulla A. Serum levels of macrophage inflammatory protein-1 alpha (MIP-1alpha) correlate with the extent of bone disease and survival in patients with multiple myeloma. Br J Haematol 2003;123:106-109.

58. Alsina M, Boyce B, Devlin RD, Anderson JL, Craig F, Mundy GR et al. Development of an in vivo model of human multiple myeloma bone disease. Blood 1996;87:1495-1501.

59. Choi SJ, Oba Y, GazittY, Alsina M, Cruz J, Anderson J et al. Antisense inhibition of macrophage inflammatory protein 1-alpha blocks bone destruction in a model of myeloma bone disease. J Clin Invest 2001;108:1833-1841.

60. Han JH, Choi SJ, Kurihara N, Koide M, ObaY, Roodman GD. Macrophage inflammatory protein1alpha is an osteoclastogenic factor in myeloma that is independent of receptor activator of nuclear factor kappaB ligand. Blood 2001;97:3349-3353.

61. Lentzsch S, Gries M, Janz M, Bargou R, Dorken B, Mapara MY. Macrophage inflammatory protein 1-alpha (MIP-1 alpha) triggers migration and signaling cascades mediating survival and proliferation in multiple myeloma (MM) cells. Blood 2003;101:3568-3573.

62. Menu E, De Leenheer E, De Raeve H, Coulton L, Imanishi T, Miyashita K et al. Role of CCR1 and CCR5 in homing and growth of multiple myeloma and in the development of osteolytic lesions: a study in the 5TMM model. Clin Exp Metastasis 2006;23:291-300.

63. Vallet S, Raje N, Ishitsuka K, Hideshima T, Podar K, Chhetri S et al. MLN3897, a novel CCR1 inhibitor, impairs osteoclastogenesis and inhibits the interaction of multiple myeloma cells and osteoclasts. Blood 2007;110:3744-3752.

64. Gladue RP, Brown MF, Zwillich SH. CCR1 antagonists: what have we learned from clinical trials. Curr Top Med Chem 2010;10:1268-1277.

65. Lee JW, Chung HY, Ehrlich LA, Jelinek DF, Callander NS, Roodman GD et al. IL-3 expression by myeloma cells increases both osteoclast formation and growth of myeloma cells. Blood 2004;103:2308-2315.

66. Ehrlich LA, Chung HY, Ghobrial I, Choi SJ, Morandi F, Colla S et al. IL-3 is a potential inhibitor of osteoblast differentiation in multiple myeloma. Blood 2005;106:1407-1414.

67. Silbermann R, Bolzoni M, Storti P, Palma BD, Bonomini S, Anderson J et al. Bone marrow monocyte/macrophage derived activin A mediates the osteoclastogenic effects of IL-3 in myeloma. Blood 2011;118:3933. 
68. Fuller K, Bayley KE, Chambers TJ. Activin A is an essential cofactor for osteoclast induction. Biochem Biophys Res Commun 2000;268:2-7.

69. Terpos E, Kastritis E, Christoulas D, Gkotzamanidou M, Eleutherakis-Papaiakovou E, Kanellias $\mathrm{N}$ et al. Circulating activin-A is elevated in patients with advanced multiple myeloma and correlates with extensive bone involvement and inferior survival; no alterations postlenalidomide and dexamethasone therapy. Ann Oncol 2012 (e-pub ahead of print 6 April 2012 doi:10.1093/annonc/mds068).

70. Chantry AD, Heath D, Mulivor AW, Pearsall S, Baud'huin M, Coulton L et al. Inhibiting activin-A signaling stimulates bone formation and prevents cancer-induced bone destruction in vivo. J Bone Miner Res 2010;25:2633-2646.

71. Ruckle J, Jacobs M, Kramer W, Pearsall AE, Kumar R, Underwood KW et al. Single-dose randomized, double-blind, placebo-controlled study of ACE-011 (ActRIIA-lgG1) in postmenopausal women. J Bone Miner Res 2009;24:744-752.

72. Kurihara N, Bertolini D, Suda T, Akiyama Y, Roodman GD. IL-6 stimulates osteoclast-like multinucleated cell formation in long term human marrow cultures by inducing $\mathrm{IL}-1$ release. J Immunol 1990;144:4226-4230.

73. Sati HI, Apperley JF, Greaves M, Lawry J, Gooding R, Russell RG et al. Interleukin-6 is expressed by plasma cells from patients with multiple myeloma and monoclonal gammopathy of undetermined significance. Br J Haematol 1998:101:287-295.

74. Rossi JF, Fegueux N, Lu ZY, Legouffe E, Exbrayat C, Bozonnat MC et al. Optimizing the use of anti-interleukin-6 monoclonal antibody with dexamethasone and $140 \mathrm{mg} / \mathrm{m} 2$ of melphalan in multiple myeloma: results of a pilot study including biological aspects. Bone Marrow Transplant 2005;36:771-779

75. Shiozawa Y, Havens AM, Jung Y, Ziegler AM, Pedersen EA, Wang J et al. Annexin II/annexin II receptor axis regulates adhesion, migration, homing, and growth of prostate cancer. $J$ Cell Biochem 2008;105:370-380.

76. Claudio JO, Masih-Khan E, Tang H, Goncalves J, Voralia M, Li ZH et al. A molecular compendium of genes expressed in multiple myeloma. Blood 2002;100:2175-2186.

77. Bao H, Jiang M, Zhu M, Sheng F, Ruan J, Ruan C. Overexpression of annexin II affects the proliferation, apoptosis, invasion and production of proangiogenic factors in multiple myeloma. Int J Hematol 2009;90:177-185.

78. Zhao C, Irie N, Takada Y, Shimoda K, Miyamoto T, Nishiwaki T et al. Bidirectional ephrinB2EphB4 signaling controls bone homeostasis. Cell Metab 2006;4:111-121.

79. Pennisi A, Ling W, Li X, Khan S, Shaughnessy Jr JD, Barlogie B et al. The ephrinB2/EphB4 axis is dysregulated in osteoprogenitors from myeloma patients and its activation affects myeloma bone disease and tumor growth. Blood 2009;114:1803-1812.

80. Kobayashi T, Kronenberg $\mathrm{H}$. Minireview: transcriptional regulation in development of bone. Endocrinology 2005;146:1012-1017.

81. Giuliani N, Colla S, Morandi F, Lazzaretti M, Sala R, Bonomini S et al. Myeloma cells block RUNX2/CBFA1 activity in human bone marrow osteoblast progenitors and inhibit osteoblast formation and differentiation. Blood 2005;106:2472-2483.
82. Yaccoby S, Wezeman MJ, Zangari M, Walker R, Cottler-Fox M, Gaddy D et al. Inhibitory effects of osteoblasts and increased bone formation on myeloma in novel culture systems and a myelomatous mouse model. Haematologica 2006;91:192-199.

83. Li X, Pennisi A, Yaccoby S. Role of decorin in the antimyeloma effects of osteoblasts. Blood 2008;112:159-168

84. Baron R, Rawadi G, Roman-Roman S. Wnt signaling: a key regulator of bone mass. Curr Top Dev Biol 2006;76:103-127.

85. Tian E, Zhan F, Walker R, Rasmussen E, Ma Y, Barlogie B et al. The role of the Wnt-signaling antagonist DKK1 in the development of osteolytic lesions in multiple myeloma. $N$ Engl J Med 2003;349:2483-2494

86. Giuliani N, Morandi F, Tagliaferri S, Lazzaretti M, Donofrio G, Bonomini S et al. Production of Wnt inhibitors by myeloma cells: potential effects on canonical Wnt pathway in the bone microenvironment. Cancer Res 2007;67:7665-7674.

87. Fulciniti M, Tassone P, Hideshima T, Vallet S, Nanjappa P, Ettenberg SA et al. Anti-DKK1 mAb (BHQ880) as a potential therapeutic agent for multiple myeloma. Blood 2009;114:371-379.

88. Brunetti G, Oranger A, Mori G, Specchia G, Rinaldi E, Curci P et al. Sclerostin is overexpressed by plasma cells from multiple myeloma patients. Ann NY Acad Sci2011;1237:19-23.

89. Terpos E, Christoulas D, Katodritou E, Bratengeier C, Gkotzamanidou M, Michalis E et al. Elevated circulating sclerostin correlates with advanced disease features and abnormal bone remodeling in symptomatic myeloma: reduction post-bortezomib monotherapy. Int J Cancer 2011 (e-pub ahead of print 2 November 2011; doi:10.1002/ijc.27342)

90. Costa AG, Bilezikian JP.Sclerostin: therapeutic horizons based upon its actions. Curr Osteoporos Rep 2012;10:64-72.

91. Giuliani N, Ferretti M, Bolzoni M, Storti P, Lazzaretti M, Dalla Palma B et al. Increased osteocyte death in multiple myeloma patients: role in myeloma-induced osteoclast formation. Leukemia 2012;26:1391-1401.

92. Takeuchi K, Abe M, Hiasa M, Oda A, Amou H, Kido S et al. TGF-beta inhibition restores terminal osteoblast differentiation to suppress myeloma growth. PLoS One 2010;5:e9870.

93. Standal T, Abildgaard N, Fagerli UM, Stordal B, Hjertner O, Borset M et al. HGF inhibits BMPinduced osteoblastogenesis: possible implications for the bone disease of multiple myeloma Blood 2007; 109:3024-3030.

94. D'Souza S, Del Prete D, Jin S, Sun Q, Huston AJ, Kostov FE et al. Gfi1 expressed in bone marrow stromal cells is a novel osteoblast suppressor in patients with multiple myeloma bone disease. Blood 2011:118:6871-6880.

95. Jin S, D'Souza S, Sun Q, Sammut B, Grimes HL, Roodman GD et al. The transcription repressor Gfi1 directly interacts with the Runx2 gene in osteoblast precursors to mediate repression by multiple myeloma cells via TNF- $\alpha$, leading to blocked osteoblast differentiation. J Bone Miner Res 2011;26 (S1):S180

96. Fowler JA, Lwin ST, Drake MT, Edwards JR, Kyle RA, Mundy GR et al. Host-derived adiponectin is tumor-suppressive and a novel therapeutic target for multiple myeloma and the associated bone disease. Blood 2011;118:5872-5882. 